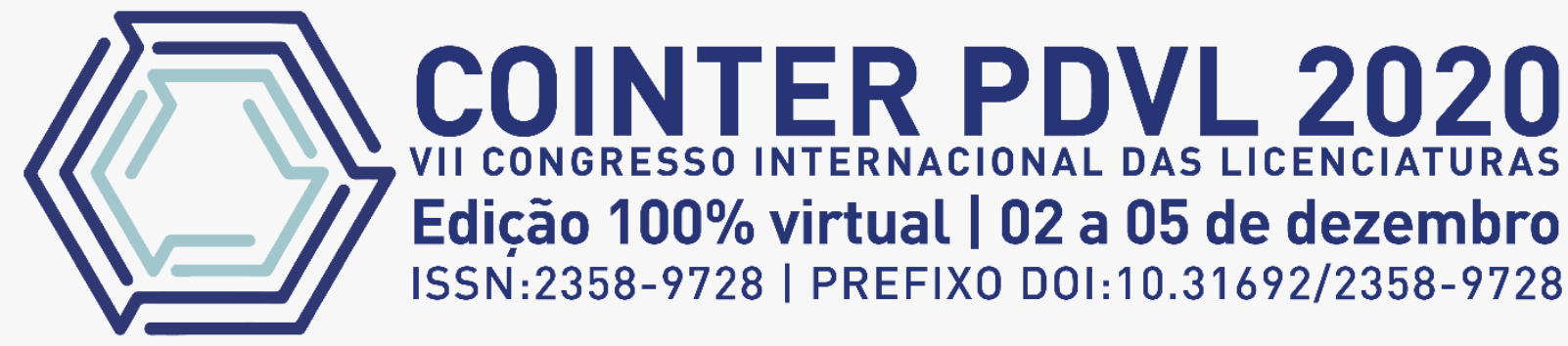

\title{
METODOLOGIAS DE ENSINO: ARTICULAÇÃO DOCENTE PARA O ENSINO DE GEOMETRIA ESPACIAL À ESTUDANTES, EM TEMPOS DA COVID-19
}

\author{
METHODOLOGIES OF TEACHING: ARTICULATION TEACHER TO THE \\ TEACHING OF SPECIAL GEOMETRY FOR STUDENTS, IN TIMES OF COVID-19
}

\section{ENSEÑANZA DE METODOLOGÍAS: ARTICULACIÓN DE PROFESOR PARA EL ENSEÑANZA DE GEOMETRÍA ESPACIAL PARA ESTUDIANTES, EN TIEMPOS DE LA COVID-19}

\author{
Apresentação: Comunicação Oral \\ Júlio César da Silva ${ }^{1}$; Déric Vinícius dos Santos ${ }^{2}$; Elyston Henrique da Silva Barros ${ }^{3}$; Luan Danilo Silva dos \\ Santos $^{4}$; Yrailma Katharine de Sousa ${ }^{5}$
}

DOI: https://doi.org/10.31692/2358-9728.VIICOINTERPDVL.0167

\begin{abstract}
RESUMO
A pandemia da COVID-19 impactou significativamente a sociedade, seja por questões econômicas, educacionais ou de saúde. A partir dela, exigências governamentais foram postas, e uma delas envolveu a adoção de medidas de distanciamento para controle da disseminação do SARS-CoV-2 (vírus da COVID-19), inclusive no contexto escolar, em que o ensino presencial precisou ser suspenso. Nesse contexto, como alternativa para continuidade de atividades educacionais, muitas instituições de ensino brasileiras passaram a trabalhar o ensino remoto, tendo como suporte Tecnologias Digitais da Informação e da Comunicação (TDICs). As TDICs podem ser um instrumento importante no desenvolvimento das práticas docentes, inclusive em atividades de ensino matemático, como por exemplo, geometria espacial. Neste sentido, objetivamos nessa pesquisa analisar, quando houvesse, a utilização de recursos metodológicos do docente para o desenvolvimento do ensino de geometria espacial à estudantes do Ensino Médio, em tempos de COVID-19. Metodologicamente, a pesquisa foi classificada numa abordagem qualitativa do tipo descritiva, e teve como técnica de coleta de dados o uso de um formulário eletrônico, com questões abertas. Como participantes tivemos três professores de matemática de uma escola da rede estadual de Camocim de São Félix-PE, que estavam ensinando ou iriam ensinar geometria espacial no ensino médio na modalidade de ensino remoto. Utilizamos a análise de conteúdo para analisar os dados obtidos. Das inferências, contatamos que os docentes utilizam vários recursos tecnológicos para o desenvolvimento de suas práticas para o ensino de geometria espacial, para
\end{abstract}

\footnotetext{
1 Graduando em Licenciatura em Matemática, Universidade Federal de Pernambuco - UFPE, cesarmatematicaufpe@gmail.com

${ }^{2}$ Graduando do Curso de Licenciatura em Matemática, Universidade Federal de Pernambuco - UFPE, dericvinicius10@gmail.com,

3 Graduando do Curso de Licenciatura em Matemática, Universidade Federal de Pernambuco - UFPE, elystonhenrique@hotmail.com.br

4 Mestre em Educação em Ciências e Matemática, Universidade Federal de Pernambuco - UFPE, danilo.1dss@hotmail.com

${ }^{5}$ Mestra em Educação em Ciências e Matemática, Universidade Federal de Pernambuco - UFPE, yrailma$\underline{\text { scc@hotmail.com }}$
} 
facilitar a compreensão e visualização do conteúdo. Esses recursos remetem dos professores investigados certa articulação para aplicação de novas metodologias de ensino, nas aulas de matemática. Verificamos ainda, alguns desafios apresentados pelos professores, como a falta de recursos dos discentes e a formação docente. Assim sendo, concluímos que o uso das TDICs tem sido um grande aliado na articulação e apresentação do conteúdo de geometria espacial, mas para que sua potencialidade seja aproveitada no processo de apresentação do conteúdo de geometria espacial é necessário que os professores estejam instrumentalizados quanto ao uso desses instrumentos. Ademais, verificamos a necessidade de reflexão acerca dos desafios advindos do modelo de ensino remoto.

Palavras-Chave: Ensino Remoto, TDICs, Geometria espacial, Metodologias

\section{RESUMEN}

La pandemia de COVID-19 ha impactado significativamente a la sociedad, ya sea por razones económicas, educativas o de salud. A partir de ahí, se establecieron requisitos gubernamentales, y uno de ellos implicó la adopción de medidas a distancia para controlar la propagación del SARS-CoV-2 (virus COVID-19), incluso en el contexto escolar, en el que se tuvo que suspender la enseñanza presencial. En este contexto, como alternativa para la continuación de las actividades educativas, muchas instituciones educativas brasileñas comenzaron a trabajar en la educación a distancia, teniendo como soporte las Tecnologías de la Información y la Comunicación Digitales (TDIC). Los TDIC pueden ser una herramienta importante en el desarrollo de prácticas de enseñanza, incluso en actividades de enseñanza de matemáticas, como la geometría espacial. En este sentido, nuestro objetivo en esta investigación es analizar, cuando hubo, el uso de recursos metodológicos del profesor para el desarrollo de la enseñanza de la geometría espacial a estudiantes de secundaria, en tiempos del COVID-19. Metodológicamente, la investigación se clasificó en un enfoque cualitativo de tipo descriptivo, y la técnica de recolección de datos fue el uso de un formulario electrónico, con preguntas abiertas. Como participantes contábamos con tres profesores de matemáticas de una escuela de la red estatal de Camocim de São Félix-PE, que estaban enseñando o enseñarían geometría espacial en el bachillerato en la modalidad de enseñanza a distancia. Utilizamos el análisis de contenido para analizar los datos obtenidos. A partir de las inferencias, encontramos que los docentes utilizan diversos recursos tecnológicos para desarrollar sus prácticas de enseñanza de la geometría espacial, para facilitar la comprensión y visualización del contenido. Estos recursos envían a los docentes investigados una cierta articulación para la aplicación de nuevas metodologías de enseñanza en las clases de matemáticas. También verificamos algunos desafíos que presentan los docentes, como la falta de recursos de los estudiantes y la formación de los docentes. Por tanto, concluimos que el uso de TDICs ha sido un gran aliado en la articulación y presentación del contenido de la geometría espacial, pero para que su potencialidad se aproveche en el proceso de presentación del contenido de la geometría espacial.

Palabras Clave: Enseñanza remota, TDICs, Geometía espacial, Metodologias

\section{ABSTRACT}

The COVID-19 pandemic impacted significantly the society, economic, educational or health reasons. From there, governmental requirements were put in place, and one of them involved the adoption of distance measures to control the spread of SARS-CoV-2 (COVID-19 virus), including in the school context, in which face-to-face teaching had to be suspended. In this context, as an alternative for the continuation of educational activities, many schools brazilian's started to work on home school, having as support Digital Information and Communication Technologies (TDICs). TDICs can be an important tool in the development of teaching practices, including in mathematical teaching activities, such as spatial geometry. In this sense, we aim in this research to analyze, when there was, the use of methodological resources of the teacher for the development of the teaching of spatial geometry to high school students, in times of COVID-19. Methodologically, the research was classified in a qualitative approach of the descriptive type, and the data collection technique was the use of an electronic form, with open questions. As participants we had three mathematics teachers from a school in the state network of Camocim de São Félix-PE, who were teaching or would teach spatial geometry in high school in the remote teaching modality. We used content analysis to analyze the data obtained. From the inferences, we find that the teachers use various technological resources to develop their practices for teaching spatial geometry, to facilitate the understanding and visualization of the content. These resources send the investigated teachers a certain articulation for the application of new teaching 
methodologies in mathematics classes. We also verified some challenges presented by teachers, such as the lack of resources from students and teacher training. Therefore, we conclude that the use of TDICs has been a great ally in the articulation and presentation of the spatial geometry content, but for its potential to be used in the process of presenting the spatial geometry content, teachers must be instrumentalized in the use of these instruments. Furthermore, we see the need for reflection on the challenges arising from the model of remote education.

Keywords: Home School, TDICs, Spatial Geometry, Methologies

\section{INTRODUÇÃO}

O ano de 2020 iniciou com a notícia do surgimento de uma nova doença denominada de COVID-19, ocasionada pelo coronavírus, SARS-CoV-2 ${ }^{6}$. Por ter um índice de apresentação muito alto, no dia 11 de março de 2020, a Organização Mundial da Saúde declarou estado de emergência com o início de uma pandemia ${ }^{7}$. Por se deflagrar de forma acelerada, medidas precisaram ser tomadas na tentativa de reduzir os impactos causados pela doença.

$\mathrm{Na}$ tentativa de conter o contágio, o isolamento social foi o principal caminho que as autoridades sanitárias recomendaram. Com isso, a vida social, econômica e educacional foi afetada perante essas medidas. A pandemia proporcionou novos comportamentos sociais, e os impactos causados por ela, influenciou em nossa forma de se relacionar, de consumo, nas nossas estratégias de trabalho, inclusive no trabalho docente (BARRETO; ROCHA, 2020). Perante as medidas de isolamento, escolas e instituições de ensino suspenderam o ensino presencial. Com isso, o Ministério da Educação (MEC) iniciou um processo de retomada das aulas, respeitando o distanciamento.

O ensino remoto foi o caminho encontrado para a retomada das atividades escolares, foi uma medida emergencial que se assemelha ao Ensino à Distância (EAD), que se trata de um modelo mediado pelo uso de recursos tecnológicos. Entendemos que essa modalidade de ensino é um desafio para alguns docentes, pois é uma nova forma de compartilhar conhecimento, uma vez que as Tecnologia Digitais de Informação e Comunicação (TDICs) na educação, muitas vezes, não é dominada por docentes, seja por falta de conhecimento da ferramenta, ou por estarem culturalmente habituados com metodologias tradicionais. Apesar dos contrapontos, cabe destacar que acreditamos que as TDICs apresentam potencialidade para o desenvolvimento significativo de práticas de ensino, principalmente no conteúdo de geometria espacial.

A geometria espacial é um campo da matemática que está relacionado com o nosso cotidiano. Contudo, ainda é muito discutido a desvalorização do ensino de geometria nas

${ }^{6}$ Corona vírus pertence a uma família de vírus presente em animais, que causa complicações respiratórias (OMS, 2020).

${ }^{7}$ Segundo a OMS (2020) uma pandemia ocorre quando o contágio de uma doença tem proporções mundial. 


\section{METODOLOGIAS DE ENSINO: ARTICULAÇÃO DOCENTE PARA O ENSINO DE}

escolas. Por isso, o uso das TDICs tem sido como uma ferramenta de ensino com potencialidade para apresentação de conteúdos, uma vez que os usos desses recursos podem facilitar a compreensão e visualização dos discentes do conceito matemático.

Pensando nisso, tomamos a iniciativa de desenvolver esta pesquisa na tentativa de responder o questionamento: De que maneira, em tempos da COVID-19, os docentes da rede pública têm desenvolvido suas metodologias didáticas para atender ao ensino de geometria espacial à estudantes do Ensino Médio? Perante esta indagação, buscamos analisar, quando houver, a utilização de recurso metodológico do docente para o desenvolvimento do ensino de geometria espacial à estudantes do Ensino Médio. Para isso, tivemos como objetivos específicos: i) identificar quais os recursos tecnológicos e como eles são adotados para o desenvolvimento do ensino de geometria espacial à estudantes do Ensino Médio; ii) verificar como docentes articulam suas práticas didáticas para o desenvolvimento do ensino de geometria espacial à estudantes do Ensino Médio e iii) verificar quais os desafios que os docentes de matemática de Camocim-PE enfrentam no modelo de ensino remoto.

Diante do exposto, julgamos relevante discutir quais os desafios que os professores encontram ao articularem suas práticas de ensino, e como as tecnologias podem contribuir no processo de ensino e aprendizagem, para disseminação de abordagens e alternativas relacionadas às práticas de ensino em tempos de COVID-19.

\section{FUNDAMENTAÇÃO TEÓRICA}

De acordo com a Organização Mundial da Saúde (OMS), no dia 30 de janeiro de 2020, surgiu um surto causado por uma doença denominada de novo Coronavírus (SARS-CoV-2) causador da COVID-19. Estabelecendo assim, uma Emergência de Saúde Pública de Importância Internacional (o mais alto nível de alerta da Organização, conforme previsto no Regulamento Sanitário Internacional). No dia 11 de março de 2020, a OMS declarou que se tratava de uma pandemia da COVID-19. Segundo o Ministério da Saúde, o primeiro caso no Brasil foi registrado no dia 26 de fevereiro de 2020, na cidade de São Paulo ${ }^{8}$. Desde então, ocorreu um processo de apresentação comunitária e o vírus se alastrou por todo país ${ }^{9}$. Com o avanço da pandemia, o número de casos foi crescendo a cada dia, colapsando os sistemas de saúde. Com isso, a sociedade precisou se precaver para redução do número de infectados. "Os

\footnotetext{
${ }^{8}$ Para mais informações, ver notícia em: https://www.saude.gov.br/noticias/agencia-saude/46435-brasil-confirmaprimeiro-caso-de-novo-coronavirus. Acesso em: 10 de agosto de 2020

${ }^{9}$ A apresentação comunitária é quando não se sabe a origem da apresentação sem poder ser identificada (OMS, 2020).
} 
processos de redução de infecção em todos os lugares do mundo se dão pelo isolamento e quarentena da sociedade, higienização e medidas para pormenorizar as contaminações" (MACEDO; ORNELLAS; BONFIM, 2020, p. 6). O isolamento social foi o principal método adotado na tentativa de conter o contágio, o que ocasionou fechamento de escolas.

De acordo com Oliveira e Souza (2020), a pandemia do novo Coronavírus tem exigido da sociedade criatividade para tentar reduzir os impactos causados por ela. Ainda conforme os autores, é nesse contexto, que no sistema educacional, Tecnologias Digitais da Informação e Comunicação (TDICs) estão sendo colocadas com mais ênfase em práticas pedagógicas, como alternativa para reestabelecer os trabalhos escolares.

As TDICs possibilitam a apresentação de informação, comunicação e interação entre pessoas de toda parte do mundo, por meio de vários artefatos como computadores, ebooks, gravador de áudio, vídeo entre outros (BARROS, 2014).

Acerca disso, acreditamos que esses artefatos podem proporcionar a interação entres as pessoas de toda parte do mundo, e que por consequência, essas interações podem influenciar na realidade dos indivíduos que fazem uso deles.

Conforme Barros (2014), essas interações interferem diretamente em nossa forma de pensar, agir, em nossos relacionamentos e ainda na forma de adquirirmos conhecimento, e, por isso, apresentar metodologias com recursos tecnológicos, muitas vezes é considerada uma ação difícil para docentes com pouca formação em relação ao uso desses recursos. De acordo com Costa (2014), a formação de alguns docentes no que se refere ao uso das tecnologias é deficiente, e em alguns casos, nunca houve.

Nesse contexto, Miskulin (1999) ressalta que educar em uma sociedade da informação, vai além do que um simples treinamento para o uso das tecnologias; é necessário formar os docentes, para que estes ensinem aos discentes "aprender a aprender", com o objetivo de prepará-los para os avanços acelerados do conhecimento tecnológico. Em consonância com a discussão Ernest (1991, p.13) apud Miskulin et al. (2006, p. 4) destaca, "a escola, em particular a sala de aula de Matemática, é o lugar no qual as crianças precisam ser preparadas para o mundo de amanhã, especialmente nos aspectos tecnológicos”.

Com isso, acreditamos que o uso das TDICs no processo de ensino e aprendizagem é fundamental para estabelecer a comunicação entres os indivíduos no contexto de aulas remotas. Esse modelo de aulas remotas possibilita que os discentes possam estudar por meio de recursos móvel (como celular, notebooks, tablets entre outros) podendo estabelecer uma sala de aula móvel. Chang; Sheu e Chan (2003) afirmam que existem quatro elementos que são essenciais para um modelo de sala de aula móvel, que são: os estudantes, os professores, os dispositivos e 


\title{
METODOLOGIAS DE ENSINO: ARTICULAÇÃO DOCENTE PARA O ENSINO DE
}

os instrumentos que servirão para estabelecer a comunicação entre eles.

A aprendizagem móvel ${ }^{10}$ entende que através da comunicação pode ser garantido o processo de construção do conhecimento através dos múltiplos contextos entre as pessoas e as tecnologias. O foco dessa aprendizagem, está sobretudo na interação comunicativa entre o aprendente e a tecnologia para buscar o avanço no conhecimento (SHARPLES; TAYLOR; VAVOULA, 2007).

Em consonância com os autores, pensamos que essa relação entre sujeito e tecnologia é fundamental no processo de ensino e aprendizagem, à medida que são projetados para estimular a criatividade e o raciocínio. Acreditamos que esses recursos podem facilitar na compreensão do conteúdo de matemática, pois a matemática é vista por muitos discentes como uma disciplina que apresenta muitas dificuldades. Enfatizando essa discussão, destacamos Bianchi (2003), que diz:

\begin{abstract}
[...] o computador deve ser visto como um recurso didático que traz uma gama enorme de possibilidades ao processo ensino-aprendizagem. Não se deve perder de vista que seu caráter lógico-matemático pode ser um bom aliado do desenvolvimento cognitivo dos alunos, por permitir distintos ritmos de aprendizagem. E também por ser ele próprio uma fonte de conhecimento, uma ferramenta para desenvolver habilidades, do aprendizado a partir de erros e interagindo com outras crianças, nas ações de troca e comparação (BIANCHI, 2003, p.68-69).
\end{abstract}

Em Matemática, toda a comunicação se estabelece com base em representações. Os objetos a serem estudados são conceitos, propriedades, estruturas, relações que podem expressar diferentes situações, portanto, para o seu ensino precisamos levar em consideração as diferentes formas de representação de um mesmo objeto matemático (DAMM, 1999).

Dentre esses objetos, a geometria espacial é um conteúdo onde o uso da tecnologia pode ajudar bastante no processo de ensino e aprendizagem, pois o uso da tecnologia pode facilitar na construção, visualização e manipulação do objeto. Uma das grandes dificuldades no ensino da geometria espacial, é a relação com dia-dia. Segundo Maia (2000, p. 32) [...] apesar da geometria ser considerada como um conteúdo que tem uma forte relação com a realidade, "na prática", ela é sobretudo "trabalhada" na sua versão mais abstrata, por isso, o uso do computador, por exemplo, é um facilitador na compreensão deste conteúdo.

Assim, pensamos que, as representações tridimensionais e sua ilustração no plano apresentam melhor possibilidade para compreensão do conteúdo de geometria espacial por parte dos discentes, mas para isso, entendemos ser necessário a instrumentalização de recursos

\footnotetext{
${ }^{10}$ Aprendizagem móvel é o conceito que representa a aprendizagem entregue ou suportada por meio de dispositivos de mão tais como smartphones, iPods, notebook's, computadores, tablets e outros pequenos dispositivos digitais que carregam ou manipulam informações (GRACIELA; FONSECA, 2013, p. 169).
} 
adequados nas práticas docentes.

Concluímos a discussão informando que, adiante, será apresentado a metodologia e os principais resultados do estudo sobre como os professores do ensino médio estão articulando suas práticas no ensino de geometria espacial com o uso da tecnologia e quais os desafios que eles estão enfrentando nesta modalidade de ensino.

\section{METODOLOGIA}

Para tentar responder a indagação: De que maneira, em tempos da COVID-19, docentes da rede pública têm desenvolvido suas metodologias didáticas para atender ao ensino de geometria espacial à estudantes do Ensino Médio?, esta pesquisa buscou analisar, quando houvesse, a utilização do recurso metodológico do docente para o desenvolvimento do ensino de geometria espacial à estudantes do Ensino Médio no período supracitado.

Para isso, o estudo foi classificado como uma pesquisa qualitativa do tipo descritiva, que de acordo com Gil (2002) é uma classificação que apresenta potencialidade para descrever as características de determinados fenômenos e suas relações com outras variáveis.

O desenvolvimento da pesquisa aconteceu em Camocim de São Félix-PE e teve como participantes, três Docentes de Matemática de uma Escola de Rede Estadual de Camocim-PE, que foram selecionados por apresentarem disponibilização para pesquisa e, principalmente por ministrarem no Ensino Médio a disciplina Matemática, que conforme D’Ambrosio (2013) apresentam ideias que comparecem por toda a evolução da humanidade, envolvidas em contextos sociais, económicos, políticos e ideológicos. Buscamos professores que lecionavam no ensino médio entre turmas do primeiro, segundo e terceiro ano, por estarem de acordo com os objetivos desta pesquisa.

Para produção dos dados utilizamos como instrumento, um questionário eletrônico do Google forms (plataforma eletrônica), "pode-se definir questionário como a técnica de investigação composta por um conjunto de questões que são submetidas a pessoas com o propósito de obter informações [...]” (GIL, 2008, p. 121). A organização do questionário envolveu questões abertas que foram respondidas individualmente pelos(as) participantes.

No tocante a análise dos dados, tomamos como base a análise de conteúdo, que conforme Bardin (1977) consiste em um conjunto de técnicas de análise que descrevem conteúdos de mensagens, identificando palavras chaves e verificando semelhanças nas respostas de participantes da pesquisa. Assim, os conteúdos obtidos por meio do questionário, foram organizados, categorizados e inferidos.

Por fim, salientamos que para preservar a identidade dos(as) participantes, optamos por 
denominá-los, nessa pesquisa, por: P1, P2 e P3. O Quadro 1 exibe as categorias elaboradas durante a análise da pesquisa:

Quadro 1 - Categorias de Análise

\begin{tabular}{|l|lllll|}
\hline Categoria 1 & $\begin{array}{l}\text { RECURSO TECNOLÓGICOS ADOTADOS PARA O ENSINO DE GEOMETRIA } \\
\text { ESPACIAL }\end{array}$ \\
\hline Categoria 2 & $\begin{array}{l}\text { ARTICULAÇÃO DOS DOCENTES COM PRÁTICAS DIDÁTICAS PARA } \\
\text { DESENVOLVIMENTO DO ENSINO DE GEOMETRIA ESPACIAL }\end{array}$ \\
\hline Categoria 3 & DESAFIOS DOCENTES: ENSINO DE MATEMÁTICA NO MODELO REMOTO \\
\hline
\end{tabular}

Fonte: Dos autores (2020)

\section{RESULTADOS E DISCUSSÃO}

Apresentaremos a seguir, alguns estratos das respostas colocadas pelos(as) participantes no questionário elaborado, além disso, inferências para evidenciar pontos observados nas categorias mencionadas anteriormente.

\section{RECURSOS TECNOLÓGICOS ADOTADOS PARA O ENSINO DE GEOMETRIA ESPACIAL}

A fim de identificar quais os recursos tecnológicos e como eles são adotados para o desenvolvimento do ensino de geometria espacial à estudantes do Ensino Médio, indagamos aos(as) participantes "Quais os recursos tecnológicos que você utiliza em suas práticas didáticas na modalidade de ensino remoto e o porquê você opta por eles?.

Daí pudemos perceber que ferramentas do Google; em especial o Google meet e Google classroom $^{11}$; ferramentas da Microsoft $^{12}$ voltadas para educação como, o Word e o Power Point 13, e instrumentos de vídeo, são os principais recursos utilizados pelos participantes da pesquisa em suas práticas de ensino na modalidade de ensino remoto. Como podemos ver nos estratos $\mathrm{P} 1$ e P3, respectivamente:

\footnotetext{
"Google classroom, ferramentas google (em especial, o google meet), ferramentas microsoft (em especial, powerpoint) [...] (sic)".
}

“Uso o Meet, google classroon, e progamas como Word e Power Point (sic)."

Esses recursos possibilitam aos professores criar, gravar e apresentar os conteúdos que

\footnotetext{
11 O Google Meet é uma ferramenta do Google que permite aos usuários fazerem reuniões online, tanto pelo computador, quanto por dispositivos móveis como celular e tablets (Disponível em: https://gsuite.google.com/intl/pt-BR/). Enquanto, o Google Classroom é uma sala de aula online, que ajuda professores na articulação de atividades e criação de aulas interativas (Disponível em: https://edu.google.com/products/classroom/?modal_active=none).

12 Empresa desenvolvedora de recursos tecnológicos (Disponível em: https://www.microsoft.com/pt-br).

13 O Word e o Power Point são programas da Microsoft Office, destinados respectivamente para, edição de textos e apresentação de slides (Disponível em: https://www.microsoft.com/pt-br/education/Products/office).
} 
trabalham. A escolha desses recursos é fundamental para oferecer aprendizagem e o engajamento dos discentes, bem como é enfatizado pelo PCN, Brasil (1997):

\begin{abstract}
Quanto aos softwares educacionais, é fundamental que o professor aprenda a escolhêlos em função dos objetivos que pretende atingir e de sua própria concepção de conhecimento e de aprendizagem, distinguindo os que se prestam mais a um trabalho dirigido para testar conhecimentos dos que procuram levar o aluno a interagir com o programa de forma a construir o conhecimento (BRASIL, 1997, p. 35).
\end{abstract}

Além disso, ao verificar as respostas dos participantes, notamos que esses recursos têm influenciado no processo de ensino e aprendizagem seja por apresentarem praticidade e por haver capacitação quanto ao uso desses instrumentos, como podemos perceber no estrato de P3, que diz:

“[...] foram de fácil acesso e todas as capacitações deram ênfase a eles [...] eles (os alunos) não tiveram dificuldades em trabalhar com esses aplicativos (sic)".

Os professores destacaram o papel de cada recurso em suas práticas, como o Google Meet que está sendo utilizado nas articulações de aulas síncronas atrelado ao uso de slides elaborados por meio do programa, Power Point, para apresentação de conteúdo. Percebemos que P2 usa o Whatsapp e a sala virtual (Google Classrom) para enviar as atividades e manter a comunicação com os discentes.

\footnotetext{
"O material está sendo enviado aos alunos via whatsapp ou na nossa sala virtual (sic) (P2)".
}

Para entender melhor o processo de utilização dos recursos, aos docentes foi indagado: "Como os recursos tecnológicos tem sido utilizado na apresentação do conteúdo de geometria espacial?”. Daí surgiram estratos como:

\footnotetext{
"Estou elaborando materiais nas plataformas da microsoft e apresento e envio nas plataformas do google (sic).” (P1)

"Nas aulas, apresento pelo meet e uso slides (sic)" (P3).
}

Como pode-se perceber, embora os professores investigados tenham apresentado o uso dessas tecnologias nas aulas de matemática, não deram detalhes de como os recursos tecnológicos estão sendo utilizados na apresentação do conteúdo de geometria espacial, a ausência deste posicionamento, nos sugere que os participantes podem não ter compreendido a pergunta colocada, pois em questionamentos posteriores contemplam a ideia, explicando melhor como se dá o desenvolvimento da aula. 


\section{METODOLOGIAS DE ENSINO: ARTICULAÇÃO DOCENTE PARA O ENSINO DE}

Com tudo, pensamos que a abordagem significativa do conteúdo aos discentes tem influências de como o recurso tecnológico está sendo explorado. Neste sentido, o conhecimento das potencialidades das TDICs devem ser, a nosso ver, bem conhecidas, para um bom desenvolvimento do processo de ensino e aprendizagem.

\section{ARTICULAÇÃO dOS DOCENTES COM PRÁTiCAS DIDÁtiCAS PARA O DESENVOLVIMENTO DO ENSINO DE GEOMETRIA ESPACIAL}

Para verificar como docentes articulam suas práticas didáticas para o desenvolvimento do ensino de geometria espacial à estudantes do Ensino Médio, perguntamos aos (as) participantes "Como você articula suas práticas pedagógicas para o desenvolvimento da aula de geometria espacial", e "De que maneira você acha que os recursos tecnológicos têm influenciado para o ensino de geometria espacial em sua turma?"

No que se refere a primeira indagação, percebemos que os professores articulam suas práticas voltadas para a visualização dos discentes. Por se tratar de objetos tridimensionais, os professores alegam que organizam suas aulas pensando em recursos que facilitam a visualização e possibilitam a compreensão de algumas fórmulas e propriedades. Destacamos o estrato de P1:

"[...] traz possibilidades bem interessantes, como por exemplo a de visualizar objetos tridimensionais [...] facilitar a inferência das fórmulas de volume, e de algumas propriedades de maneira geral (sic)."

Entendemos que visualizar e representar os objetos é essencial para construção do pensamento geométrico. Sobre isso, Carvalho (2010) ressalta que a capacidade de reproduzir e representar figuras tridimensionais no plano e de analisar desenhos de sólidos geométricos, contribui para o processo de visualização espacial do discente. Além da manipulação, como ressaltado no estrato de $\mathrm{P} 2$ :

\footnotetext{
"sempre articulamos o estudo da geometria espacial com o manipulável já que estamos trabalhando com três dimensões [...] (sic)”.
}

A visualização e a representação dos desenhos geométricos podem, a nosso ver, permitir que os discentes possam relacionar os objetos geométricos com o seu entorno. Acerca disso, Souza (2011) esclarece que na aprendizagem de Geometria, a teoria e a prática devem estar intercaladas, neste caso, o contato visual e manjo dos objetos, junto a discussão teórica são importantes para abstração do conceito pelo aluno.

Sendo assim, destacamos P1 que diz que utiliza recursos como: 
"O Google Expeditions que traz possibilidades bem interessantes (similar a tecnologia utilizada em pokemon go) (sic)".

Julgamos que tecnologia com esse propósito, possibilita novas formas de aprender e ensinar matemática. Nesta perspectiva, o professor assume uma posição de mediador do conhecimento enquanto os discentes passam a ter mais atuação sobre o objeto de estudo. Em relação a isso, Lobo da Costa (2010) considera que:

\begin{abstract}
O professor como mediador deve estar centrado prioritariamente na aprendizagem e empreender ações em parceria com os estudantes. [...] é necessário que o professor desenvolva novas atitudes e que, além disso, haja uma mudança também no papel do aluno. O professor [...] deve sair da posição de conhecedor absoluto do tema em estudo e lançar-se no processo de construção do conhecimento, pondo-se em contato direto com seus discentes e, se necessário, pesquisando com eles (LOBO DA COSTA, 2010, p. 103-104).
\end{abstract}

No que se refere a segunda indagação, os (as) participantes apontaram, de maneira geral que, os recursos tecnológicos influenciam na forma como os discentes aprendem o conteúdo. Como pode ser observado nos estratos de $\mathrm{P} 2$, P1 e P3, respectivamente:

\footnotetext{
"Graças a esses recursos, a geometria espacial pode ser vista pelo menos em uma perspectiva mais abrangente, podendo girar e visualizar um sólido, por exemplo (sic)".

"Creio que as possibilidades trazidas pelos recursos facilitem a visualização das figuras e propriedades (sic)".
}

\begin{abstract}
"Sem dúvida as aulas presenciais não têm comparação, porém os recursos tem sido um grande aliado, para ambas as partes. Nesses últimos dias, eles apresentaram, para mim, um seminário de sólidos geométricos, onde eles confeccionaram sólidos e os apresentaram com suas respectivas áreas, bem proveitoso (sic).”
\end{abstract}

Sobre isso, Gravina (1996) ressalta que esses recursos interferem na maneira como os discentes aprendem, pois eles oportunizam a experimentação, criação, argumentação e dedução de propriedades matemáticas. Assim, pensamos que esse tipo de situação pode influenciar ao estudante, o desenvolvimento da criatividade, argumentação e o estabelecimento de relacões com o objeto estudado. Por isso, é algo que deve ser pensado na atuação docente, principalmente pela potencialidade de ensino e aprendizagem que as TDICs apresentam.

\title{
DESAFIOS DOCENTES: ENSINO DE MATEMÁTICA NO MODELO REMOTO
}

Com o propósito de verificar quais os desafios que os docentes de matemática de Camocim-PE enfrentam no modelo de ensino remoto, inquirimos aos (as) participantes: "Quais 
os principais desafios que você encontra para o desenvolvimento de suas metodologias, nesse período da COVID-19?" e "Como você acha que esses desafios interferem no processo de ensino e aprendizagem de seus discentes(as)?”.

No tocante a primeira pergunta, de maneira geral, os participantes apontaram que a falta de acesso dos discentes aos recursos necessários, é o principal desafio no desenvolvimento de suas metodologias. Frente aos vários problemas que a educação brasileira apresenta, a pandemia da COVID-19 trouxe consigo mais problemas devido as paralizações, por isso "os discentes terão de enfrentar um sistema de educação que não tem estrutura suficiente para ampará-los frente a essa nova realidade" (AVELINO; MENDES, 2020, p. 57).

A falta de interesse dos discentes foi outro desafio encontrado pelos professores. Neste aspecto, cabe ao professor tentar motivar seus discentes com didáticas atrativas que proporcione a interação com esses discentes. Para Bzuneck e Boruchovitch e (2004, p. 37) apud Oliveira (2019, p. 21) a motivação intrínseca proporciona ao aluno a noção de que "a participação na tarefa é a principal recompensa, não sendo necessárias pressões externas, internas ou prêmios por seu cumprimento". Neste caso, acreditamos que o professor precisa estar preparado perante esses desafios.

Neste sentido, Costa (2014) revela que a maioria dos cursos de licenciatura não ensina os professores a utilizarem as tecnologias em suas práticas de ensino. Como revela P2:

"[...] a nossa dificuldade em nunca termos imaginado que um dia o nosso trabalho seria realizado dessa maneira também é um desafio, sem uma preparação antecipada em todos os sentidos e tendo que se trabalhar pra fazer o melhor possível (sic)".

Perante os desafios apresentados pelos participantes, notamos por meio dos estratos, também obtidos pelo segundo questionamento, que a retomada das atividades presenciais é a maior preocupação por parte dos docentes. Tendo em vista, que muitos discentes não estão tendo acesso as aulas remotas, a preocupação dos professores está pautada em como atender as necessidades desses discentes e assegurar o direito a educação. Não havendo nenhuma perspectiva de retomada, como apontam P1 e P2, respectivamente:

"[...] não sabemos como tais discentes poderão ter seus direitos de aprendizados assegurados, o que gera uma aflição sobre o processo (sic)".

"Esse tempo não será apenas meses, mas carregaremos essa perca por muito tempo e acredito que não conseguiremos recuperar, infelizmente (sic)".

\section{CONCLUSÕES}

Com o surgimento da pandemia da COVID-19, e com ela a necessidade de promover 
um isolamento social, buscou-se alternativa para retomar as atividades educacionais. $\mathrm{O}$ ensino remoto foi o modelo adotado por muitas escolas para tentar promover a retomada das atividades. Observamos que esse modelo de ensino era uma novidade para muitos professores de matemática e, por isso, julgamos importante estudar de que maneira, em tempos da COVID19, os docentes da rede pública têm desenvolvido suas metodologias didáticas para atender ao ensino de geometria espacial à estudantes do Ensino Médio.

Desta forma, tivemos como objetivo geral, analisar, quando houvesse, a utilização de recurso metodológico do docente para o desenvolvimento do ensino de geometria espacial à estudantes do Ensino Médio. Constatou-se que o objetivo geral foi atendido, pois a pesquisa conseguiu identificar que as Tecnologias Digitais da Informação e Comunicação foram os principais recursos utilizados pelos professores no desenvolvimento de suas práticas no ensino de geometria espacial.

Diante disso, analisamos quais os recursos tecnológicos adotados para o ensino de geometria espacial. Notamos com isso, que a utilização de softwares, e plataformas virtuais voltadas para a educação, foram os principais recursos utilizados pelos professores em suas aulas remotas. Verificamos também, a importância que esse recurso tem desempenhado para o desenvolvimento do ensino e aprendizagem de matemática, à medida em que se era destacado, pelos docentes como se davam seus usos em sala de aula. Percebemos que, a comunicação entre professor-aluno é favorecida com essas ferramentas, e que práticas de ensino podem ser remodeladas com a integração dessas metodologias ativas.

Buscamos também, compreender como se dá a articulação dos docentes com práticas didáticas para o desenvolvimento do ensino de geometria espacial. Percebemos que os recursos tecnológicos têm contribuído para as práticas docentes no ensino de geometria espacial, uma vez que se observou uma certa articulação de docentes com as ferramentas tecnológicas, em suas aulas matemáticas, para exploração de ideias abstratas, ou de fórmulas, por exemplo. $\mathrm{O}$ que, de acordo com os participantes, foi um fator que interferiu diretamente na forma como os estudantes aprenderam o conteúdo.

Averiguamos os desafios que os docentes têm enfrentado no modelo de ensino remoto. Constatamos que a falta de recursos dos discentes tem sido o principal desafio que os docentes têm enfrentado, pois alguns alunos não estão tendo acesso as aulas, por falta de tecnologias apropriadas, o que implicou em posicionamentos que denotam preocupação dos docentes, quanto a retomada das atividades presenciais, à medida que eles não sabem como irão atender as necessidades dos discentes. Além disso, a falta de empenho dos discentes e a formação dos professores também tem sido um obstáculo nas aulas remotas. 


\section{METODOLOGIAS DE ENSINO: ARTICULAÇÃO DOCENTE PARA O ENSINO DE}

Isto posto, respondendo à questão de que maneira, em tempos da COVID-19, os docentes da rede pública têm desenvolvido suas metodologias didáticas para atender ao ensino de geometria espacial à estudantes do Ensino Médio, compreendemos que mesmo diante de alguns desafios advindos desta modalidade de ensino, os professores têm desenvolvido suas práticas com o auxílio da tecnologia para o desenvolvimento de suas aulas em tempos de COVID-19. Esses recursos tecnológicos têm possibilitado que os professores apresentem o conteúdo de geometria espacial de forma visual e compreensiva.

Concluímos com a reflexão sobre a necessidade da viabilização dos recursos tecnológicos no processo de ensino e aprendizagem matemática e a importância da formação dos docentes, para um uso eficiente das TDICs. Por fim, salientamos que novas pesquisas podem emergir para tentar solucionar algumas questões, tais como: aplicação das Tecnologias Digitais da Informação e da Comunicação na formação docentes; como o ensino remoto podese tornar acessível a todos os estudantes; e, como desenvolver metodologias de ensino eficientes no modelo de ensino remoto.

\section{REFERÊNCIAS}

AUTORES, 2020.

AVELINO, W. F.; MENDES, J. G. A. REALIDADE DA EDUCAÇÃO BRASILEIRA A PARTIR DA COVID-19. Boletim de Conjuntura (BOCA), Boa vista, v. 2, n. 5, p. 56-62, 2020.

BARDIN. L. Análise de conteúdo. Lisboa: Editora Edições 70, 1977.

BARRETO, A. C. F.; ROCHA, D. S. Covid-19 e educação: resistências, desafios e (im) possibilidades. Revista Encantar-Educação, Cultura e Sociedade, Bahia, v. 2, s.n, p. 01-11, 2020.

BRASIL. Parâmetros Curriculares Nacionais: matemática. Brasília: MEC/SEF, 1997.

BARROS, M. A. M. CONCEPÇÕES, USOS, MODELOS E ESTRATÉGIAS DA UTILIZAÇÃO DE DISPOSITIVOS MÓVEIS: uma análise da Aprendizagem Móvel entre professores de Ciências em formação. 2014, 240 f.Tese (Doutorado em Ensino das Ciência), Universidade Federal Rural de Pernambuco, UFRPE, 2014.

BIANCHI, C. Educar: ensinar a pensar. Revista Thot, São Paulo, s.v, n.79, p. 66-69, 2003.

BZUNECK, J. A.; BORUCHOVITCH, E. A motivação do aluno: contribuições da psicologia contemporânea. 3. ed. Petrópolis: Vozes, 2004.

CARVALHO, M. L. O. Representações planas de corpos geométricos tridimensionais: uma proposta de ensino voltada para a codificação e decodificação de desenhos. 2010. $243 \mathrm{f}$. 
Dissertação (Mestrado Profissional em Educação Matemática) - Universidade Federal de Ouro Preto, UFOP, 2010.

COSTA, S. M. A influência dos recursos tecnológicos no processo de ensino aprendizagem. 2014. 43 f. Trabalho de Conclusão de Curso (Especialização em Fundamentos da Educação: Práticas Pedagógicas Interdisciplinares) - Universidade Estadual da Paraíba, UEPB, 2014.

CHANG, C. Y., SHEU, J. P., CHAN, T. W. Concept and design of ad hoc and mobile classrooms. Journal of Computer Assisted Learning, v.19, n. 3, p. 336-346, 2003. Disponível em: https://onlinelibrary.wiley.com/doi/10.1046/j.0266-4909.00035.x . Acesso em: 25 de setembro de 2020.

D’AMBROSIO, U. Priorizar História e Filosofia da Matemática. Cuadernos de Investigación y Formación en Educación Matemática, Costa Rica, v. 8, n. 11, p. 175-187, 2013.

DAMM, R. F. Registros de representação. In: MACHADO, S. D. A. et al (Orgs). Educação Matemática: uma introdução. São Paulo: EDUC, 1999, p. 135-153.

OLIVEIRA, H. V.; SOUZA, F. S. Do conteúdo programático ao sistema de avaliação: reflexões educacionais em tempos de pandemia (COVID-19). Boletim de Conjuntura (BOCA), Boa vista, v. 2, n. 5, p. 15-24, 2020.

ERNEST, P. Mathematics Teaching: The State of the Art. New York: The Falmer Press, 1991.

FONSECA, A. G. M. F. Aprendizagem, Mobilidade e Convergência: Mobile Learning com Celulares e Smartphones. Revista Eletrônica do Programa de Pós-Graduação em Midia e Cotidiano, UFF, s.v, n.2, p.163-181, 2013.

GIL, A. C. Métodos e técnicas de pesquisa social. 6. ed. São Paulo: Atlas SA, 2008.

GIL, A. C. Como elaborar projetos de pesquisa. 4. ed. São Paulo: Atlas SA, 2002.

GRAVINA, M. A. Geometria Dinâmica: uma nova abordagem para o aprendizado da Geometria. In: VII SIMPÓSIO BRASILEIRO DE INFORMÁTICA NA EDUCAÇÃO, 1996, Belo Horizonte, Anais ... Porto Alegre, 1996.

LOBO DA COSTA, N. M. Reflexões sobre tecnologia e mediação pedagógica na formação do professor de matemática. In: BELINE, W.; LOBO DA COSTA, N. M. (Orgs) Educação Matemática, Tecnologia e Formação de Professores: algumas reflexões. Campo Mourão: FECILCAM, 2010, p.85 -116.

MACEDO, Y. M.; ORNELLAS, J. L.; BONFIM. H. R. COVID-19 NO BRASIL: o que se espera para população subalternizada? Revista Encantar - Educação, Cultura e Sociedade Bom Jesus da Lapa, v. 2, p. 01-10, 2020.

MAIA, L. S. L. O ensino da Geometria: analisando diferentes representações. Educação Matemática em Revista, São Paulo, ano 7, n. 8, p. 24- 33, 2000.

MISKULIN, R. et al. Identificação e Análise das dimensões que permeiam a utilização das 
tecnologias de informação e comunicação nas aulas de matemática no contexto da formação de professores, Bolema: Mathematics Education, Rio Claro, v. 19, n. 6, p. 1-16, 2006.

MISKULIN, R. G. S. Concepções Teórico-Metodológicas Sobre a Introdução e a Utilização de Computadores no Processo Ensino/Aprendizagem da Geometria. 1999, 577 f. Tese (Doutorado em Educação), Universidade Estadual de Campinas, UNICAMP, 1999.

ORGANIZAÇÃO MUNDIAL DA SAÚDE. Folha informativa - COVID-19 (doença causada pelo novo coronavírus). 2020. Disponível em: https://www.paho.org/bra/index.php?option=com_content\&view=article\&id=6101:covid19\&I temid=875. Acesso em: 25 de maio de 2020 .

OLIVEIRA, J. N. Práticas Pedagógicas que impulsionam e motivam os educandos no processo de ensino e aprendizagem: a influência da motivação como estratégia pedagógica. Paraíba, 2019. 56 f. Trabalho de Conclusão de Curso (Licenciatura em Pedagogia). Universidade Federal da Paraíba, UFPB, 2019.

SHARPLES, M.; TAYLOR, J.; VAVOULA, G. A. Theory of Learning for Mobile Age. In ANDREWS; HAYTHORNTHWAITE (Org). The Sage Handbook of Elearning Research, Londres: Sage, 2007, p. 221-247.

SOUZA, G. R. O ensino da geometria nos anos iniciais do ensino fundamental. Revista Pandora Brasil, online, n.27, s.v, p. 1-16, 2011. 